\title{
Potencial para implantação da produção mais limpa em sistemas locais de produção: o polo joalheiro de São José do Rio Preto
}

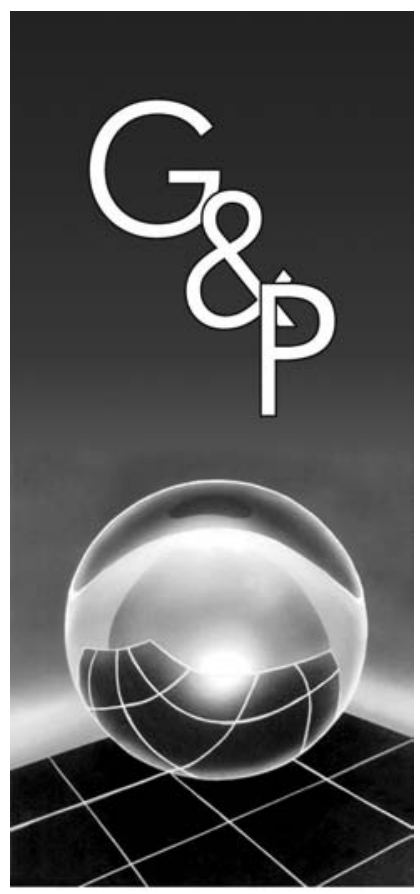

\author{
Rosely Mana Domingues \\ Sônia Regina Paulino
}

\begin{abstract}
Resumo
Os sistemas locais de produção (SLP) têm sido foco de políticas e ações nas esferas internacional e nacional voltadas ao desenvolvimento da competitividade da indústria local com base na dinamização de vantagens de aglomeração. Tais ações e políticas apontam os SLP como vetor de dinamismo econômico que favorece o desenvolvimento local, ressaltando o papel de micro e pequenas empresas (MPE) organizadas em aglomerações industriais. Porém, verifica-se que, nas análises e nas ações de estruturação e promoção dessas aglomerações, a dimensão ambiental recebe tratamento tangencial. Coloca-se, então, a questão sobre como contemplar a referida dimensão no entendimento e no desenvolvimento dos SLP, incorporando o objetivo de prevenir e reduzir os impactos ambientais negativos oriundos das atividades dessas aglomerações. O artigo tem como objetivo analisar as oportunidades para a integração da dimensão ambiental em um grupo de empresas do Polo Joalheiro de São José do Rio Preto-SP, o segundo maior do Estado de São Paulo em confecção de joias em ouro, participantes de um projeto de competitividade executado pelo Serviço Brasileiro de Apoio às Micro e Pequenas Empresas (SEBRAE). A análise proposta adota a produção mais limpa $(P+L)$ como abordagem e ferramenta de gestão ambiental particularmente adequada para empresas de menor porte e podendo convergir com esforços de inovação tecnológica para, desse modo, constituir uma
\end{abstract} alternativa para a efetivação de melhoria no desempenho ambiental. Por meio de uma pesquisa qualitativa de caráter exploratório, verificou-se que os esforços de atualização tecnológica realizados no polo joalheiro, analisados com base na $P+L$, permitem a obtenção de benefícios ambientais, econômicos e de saúde e segurança ocupacional a partir da redução no consumo de matérias-primas, água e energia, bem como na geração de resíduos e nas emissões. São identificadas oportunidades para incorporar a dimensão ambiental em políticas e ações para a promoção de SLP, levando em conta as especificidades e a dinâmica tecnológica setorial em MPE.

Palavras-chave: Produção mais limpa. Inovação tecnológica. Sistemas locais de produção. Arranjos produtivos locais. Indústria de joias.

\section{Introdução}

$\mathrm{O}$ artigo tem como objetivo analisar as oportunidades para a implantação da $\mathrm{P}+\mathrm{L}$ em políticas de apoio com foco em localidades e voltadas ao incremento da competitividade de sistemas locais de produção (SLP), tendo sido considerado, para a pesquisa empírica, o Polo Joalheiro de São José do Rio Preto-SP.

A preocupação com os agrupamentos ou aglomerações de empresas sempre esteve presente no processo de planejamento e de concepção de políticas de desenvolvimento. Porém, nos últimos anos as políticas industriais, e também as de desenvolvimento, passaram a dar maior atenção à formação de sistemas locais de produção, ou seja, de aglomerações ou agrupamentos de empresas com transações entre os agentes e a presença de instituições de pesquisa e desenvolvimento (P\&D), devido à possibilidade inerente de criar e explorar externalidades positivas (HADDAD, 2002).

Para Suzigan et al. (2001), a realização de estudos de caso e a formulação de diretrizes gerais de políticas públicas e ações coletivas adaptáveis caso a caso são temas que devem compor a agenda de pesquisa sobre aglomerações industriais no Brasil.

Pelo fato dos aglomerados produtivos serem constituídos praticamente por micro e pequenas empresas que colaboram consideravelmente com a geração de empregos e representam uma base importante para melhoria da eficiência da cadeia produtiva, as atenções de estudiosos e de várias entidades se 
voltam para essas empresas por meio de ações desenvolvidas para fortalecê-las e torná-las competitivas em um mercado altamente concorrido.

A necessidade de reduzir custos de produção, aumentar a eficiência e a competitividade dessas empresas vem ao encontro de adoção e implantação da produção mais limpa $(\mathrm{P}+\mathrm{L})$, que também contribui para a redução de multas e penalidades por poluição; facilita o acesso às linhas de crédito; melhora as condições de saúde e de segurança do trabalhador; melhora a imagem da empresa junto a consumidores, fornecedores e poder público; melhora o relacionamento com os órgãos ambientais e com a comunidade, além de proporcionar maior satisfação aos clientes (UNEP, 2002).

A P + L é definida como a aplicação contínua de estratégia integrada e preventiva de processos, produtos e serviços, para aumentar a eficiência e reduzir os riscos para o homem e o meio ambiente (UNEP, 1989).

A adoção da $\mathrm{P}+\mathrm{L}$ nas empresas pode ser considerada uma fonte de oportunidades, resultando em uma alternativa viável para a redução dos custos e o aumento da lucratividade das empresas. Porém, são considerados obstáculos para a adoção da P + L: a resistência à mudança; a falta de informação sobre a técnica e a importância dada ao meio ambiente; a inexistência de políticas nacionais de suporte às atividades de produção limpa; as barreiras econômicas (alocação incorreta dos custos ambientais e investimentos) e as barreiras técnicas (novas tecnologias) (UNIDO/UNEP, 1995). A P + L pode ser particularmente apropriada para empresas de menor porte porque não requer tecnologias sofisticadas, nem inovações radicais e nem grandes investimentos, podendo, muitas vezes, gerar benefícios ambientais e econômicos com pequeno investimento.

Verifica-se que muito se tem pesquisado e discutido sobre a implantação da $\mathrm{P}+\mathrm{L}$ na indústria, considerando micro e pequenas empresas individualmente. $\mathrm{O}$ mesmo não ocorre quando o foco da análise são aglomerações industriais de MPE. Existe, portanto, uma lacuna referente ao tratamento da dimensão ambiental na literatura dedicada à análise do desempenho e dos requisitos para a competitividade em SLP.

Nas análises e nas ações de estruturação e promoção dessas aglomerações, a dimensão ambiental recebe tratamento tangencial. Coloca-se, então, a questão sobre como contemplar a referida dimensão no entendimento e no fortalecimento dos SLP incorporando o objetivo de prevenir e reduzir os impactos ambientais negativos oriundos das atividades dessas aglomerações.

A importância em analisar este estudo de caso consiste em dois fatores de extrema relevância para a economia brasileira. Primeiramente, $73 \%$ das empresas brasileiras do setor joalheiro são compostas por microempresas, $23 \%$ de pequenas empresas e 3,9\% de médias empresas (IBGM, 2007); em segundo lugar, de acordo com a pesquisa realizada pelo Instituto Brasileiro de Gemas e Metais Preciosos - IBGM (2002), o consumo brasileiro de joias, em 2001, foi de 37 toneladas e a produção brasileira foi de apenas 24 toneladas, atendendo somente $65 \%$ do mercado nacional, sendo a diferença suprida pela importação informal, devido à alta tributação existente no País. Esta importação tem origem nos grandes produtores mundiais como Itália, China, Tailândia e Suíça, sendo reexportada informalmente via Panamá, Uruguai e Paraguai para o Brasil.

Por não haver pesquisas atualizadas sobre o consumo brasileiro de joias, não foi possível saber se a produção interna ainda não atende à demanda, pois conforme informação do IBGM (2006), no quadro "30 Maiores Países fabricantes de Joias de Ouro", o Brasil ocupa a 22 $2^{\mathrm{a}}$ posição com uma produção de 22 toneladas, ou seja, uma queda na produção de $9 \%$ em relação ao ano de 2001.

Outro fator importante a ser mencionado é que as empresas brasileiras do setor joalheiro estão inseridas na cadeia produtiva de Gemas e Joias que representa um sistema de atividades que engloba desde a extração da matéria-prima, a lapidação de pedras, a transformação em produtos e a sua comercialização. A referida cadeia está incluída entre os setores considerados dinâmicos na economia brasileira, sendo considerada prioritária no Programa Brasileiro de Qualidade e Produtividade e justificando ações implementadas pelo Ministério do Desenvolvimento, Indústria e Comércio Exterior (MDIC) em parceria com o IBGM.

Os polos joalheiros brasileiros, na sua grande maioria, são formados por micro e pequenas empresas que contribuem para a geração de emprego, exportações, abastecimento do mercado interno e desenvolvimento do local onde estão inseridos. Por representarem um importante fator de desenvolvimento local e regional devido, principalmente, às sinergias formadas pela integração de produtores de matéria-prima, prestadores de serviços, manufaturadores e comerciantes, busca-se a estruturação de micro e pequenas empresas para obtenção de ganhos de competitividade por meio de estratégias de fortalecimento da cadeia produtiva de gemas e joias (IBGM, 2005).

Esse artigo busca oferecer elementos que contribuam para o desenvolvimento e a incorporação, em políticas e ações destinadas aos SLP, de ações focadas na dimensão ambiental, por meio da adoção das ferramentas da P + L que auxiliem na apreensão das práticas e processos que visem aumentar o desempenho ambiental de aglomerações produtivas nas quais predominam empresas de menor porte. Para isso, é destacada a dinâmica tecnológica, por contribuir consideravelmente para as mudanças no processo produtivo.

Os esforços de atualização tecnológica identificados no polo joalheiro foram analisados com base na abordagem da $\mathrm{P}+\mathrm{L}$, considerando os níveis de aplicação da $\mathrm{P}+\mathrm{L}$, a escala de prioridades no gerenciamento de resíduos e os resultados em termos de benefícios econômicos.

Com relação à estrutura do trabalho, além desta introdução e da conclusão, o artigo realiza, na seção 2, uma revisão da literatura sobre sistemas locais de produção no contexto brasileiro, destacando as análises sobre dinâmica tecnológica. 
Na seção 3, são apresentados os procedimentos metodológicos da pesquisa de campo. A seção 4 é dedicada à caracterização do processo produtivo de joias e a identificação dos aspectos ambientais a ele relacionados. E na seção 5, são identificadas as oportunidades para a implantação da produção mais limpa nas empresas participantes do projeto de competitividade executado pelo SEBRAE.

\section{Tecnologia e inovação em sistemas locais de produção}

Esse item se dedica à análise das relações envolvendo sistemas locais de produção, inovação e produção mais limpa. A partir de revisão da literatura sobre SLP, são destacados o papel e relevância dos processos de inovação tecnológica. A partir daí, são tecidas considerações sobre as possibilidades de inserção da dimensão ambiental, por meio da P + L, em convergência com os esforços inovativos no escopo das políticas e ações de promoção e fortalecimento de SLP.

Tendo em conta a multiplicidade de abordagens sobre as aglomerações industriais para a finalidade deste artigo, cabe apresentar a análise voltada ao entendimento, no contexto brasileiro, de sistemas locais de produção enquanto vetor do desenvolvimento local calcado em ações focadas em localidades e no incremento da competitividade de empresas inseridas em aglomerações setoriais localizadas.

Nesse sentido, o estudo de aglomerações de empresas demonstra que esses aglomerados produtivos surgem de maneira espontânea, exploram as vocações da região e necessitam de atores públicos e privados para sua consolidação. São sistemas locais de produção associados ao processo de formação histórico periférico, sendo que a maior parte deles assume características de arranjos informais, cujo nível tecnológico é baixo e cuja capacidade de gestão é precária. A força de trabalho possui baixo nível de qualificação sem sistema contínuo de aprendizado. Por outro lado, estão ganhando uma revelada preferência pelas políticas públicas brasileiras de desenvolvimento local e regional, pois se tornam um mecanismo estruturador e organizador das micro e pequenas empresas, contribuindo para o desenvolvimento local/regional/nacional (AMARAL FILHO et al., 2002).

Passando agora ao papel e relevância dos processos de inovação em SLP, observa-se que, a partir da última década do século XX, as abordagens que privilegiam o tema da localização das atividades econômicas incorporam a tecnologia e a inovação como elementos determinantes da conformação de aglomerações produtivas. Enfatiza-se a importância do aprendizado para a atividade inovativa e a dimensão local como locus para a inovação (MIGLINO, 2003).

Considerando o contexto nacional, tal linha de argumentação é seguida por vários autores que se dedicam ao tema das aglomerações industriais a partir da abordagem em sistemas locais de produção, buscando identificar os fatores determinantes bem como os limitantes da inovação em clusters industriais.
Lastres et al. (1998) enfatizam que os processos de geração de conhecimento e de inovação são interativos e localizados. Por isso, o foco nas aglomerações industriais coloca o interesse no âmbito local como referência para o desenvolvimento endógeno.

Para Lemos (2001), devido ao universo das micro, pequenas e médias empresas ser heterogêneo e a maior parte delas operar em ambientes de baixo conteúdo tecnológico, a sua capacidade de inovação ocorre no próprio ambiente de produção, seja na incorporação de inovações originadas em outras empresas e setores, seja utilizando elementos não originados da $\mathrm{P} \& \mathrm{D}$ formal, seja a partir de práticas comuns e do uso de criatividade cotidiana na gestão de seus escassos recursos. Enfim, difundir a cultura de interação, focar os benefícios do aprendizado interativo e desenvolver a cooperação entre empresas e entre estas e outras instituições que possam contribuir para a inovação é de fundamental importância para a sobrevivência dos sistemas locais de produção.

Segundo Lastres (2004), para a implantação de políticas para promoção de arranjos produtivos e inovativos locais de micro e pequenas empresas devem-se levar em conta as especificidades dos rebatimentos locais das diferentes atividades; entender o espaço que simboliza o locus real, pois é onde ocorre o aprendizado, a criação das capacitações produtivas e inovativas e a fluidez dos conhecimentos tácitos; não ignorar a existência de disparidades que decorrem não só de fatores econômicos, mas também de diversidades nas matrizes sócio-políticas e das particularidades históricas. O foco dessas políticas deve estar voltado para a promoção dos processos de geração, aquisição e difusão de conhecimento, e fortalecimento das interações entre os diferentes agentes, para dinamizar localmente os processos de aprendizado e de inovação. Por outro lado, deve-se também fomentar a difusão do conhecimento codificado e tácito por toda a rede de agentes locais.

Já Amorim et al. (2005) apontam que tanto os aspectos ineficientes, com relação à inovação, como as interações entre os próprios agentes do aglomerado, políticas que facilitam o inter-relacionamento, o aprendizado e a inovação, a constituição e a vivência prática dessas redes de inter-relações, devem ser criados para constituir um mecanismo eficaz que facilite a evolução das aglomerações para uma estrutura mais complexa. As aglomerações produtivas não devem dar-se por realizadas e, sim, evoluírem para uma forma superior de organização, mais sistêmica, sustentável, com maior nível de interdependência entre os agentes. Essa forma superior de organização envolve empresas e outros atores locais como governo, associações, instituições de financiamento, de ensino, de formação e pesquisa. Também são desenvolvidas outras atividades correlatas que contribuem para incrementar a especialização e consequentemente estimular a cooperação e a inovação. Surgem assim, relações socioeconômicas que passam a fazer parte do processo de produção, dando origem à formação de um tecido socioprodutivo, em que os agentes se especializam, cooperam, trocam informações, aprendem 
e compartilham de um projeto comum: o desenvolvimento do conjunto de empresas.

Com base nessa dinâmica de funcionamento, aponta-se que os sistemas locais de produção podem contribuir para o aumento das exportações, geração de empregos e bem-estar social, crescimento econômico e desenvolvimento tecnológico. São considerados vetores de desenvolvimento setorial, regional e social (SUZIGAN et al., 2003).

Porém, com relação ao papel dos sistemas locais de produção na sustentabilidade ambiental de sistemas produtivos, localidades e regiões parcas menções são identificadas, sendo apresentadas de modo genérico e sem maiores desdobramentos analíticos.

O desenvolvimento sustentável é um conceito em construção e envolve várias dimensões. A definição de sustentabilidade mais difundida coloca que o desenvolvimento sustentável (DS) deve satisfazer às necessidades da geração presente sem comprometer as necessidades das gerações futuras. A dimensão ambiental do DS implica estimular as empresas a considerarem o impacto ambiental de suas atividades. Muitos recursos naturais utilizados na produção industrial são finitos, sendo que sua utilização deve ser racional, para que possam servir para a produção atual e para as gerações futuras (LUSTOSA; YOUNG, 2002; CLARO; CLARO; AMÂNCIO, 2008).

Diniz (2002), ao propor diretrizes para uma política de desenvolvimento regional, recomenda 1) a recriação de uma política regional em diferentes escalas com objetivos e instrumentos adequados; 2) as políticas específicas para aglomerados produtivos devem ser pensadas à escala local; e 3) a articulação entre políticas regionais, bem como a sua horizontalização em relação à preservação ambiental, devem ser promovidas nos termos de um compromisso com a sustentabilidade. $\mathrm{O}$ autor menciona a relevância da incorporação da dimensão ambiental como aspecto estruturante nas políticas de desenvolvimento regional, no entanto não apresenta exemplos ou elementos sobre como proceder nessa direção.

Cassiolato e Lastres (2002) apontam a fragilidade de aglomerações industriais cuja dinâmica está baseada no aproveitamento de vantagens espúrias de localização. Como exemplos dessas vantagens são mencionados o baixo custo da mão de obra e os incentivos fiscais. Assim, mesmo não apontando diretamente os problemas decorrentes da instalação de sistemas produtivos descolados de conceitos e práticas convergentes com a proteção e conservação ambiental, os autores fazem referência às vantagens baseadas em elementos que comprometem a sustentabilidade das atividades econômicas. Entretanto, esse tema é retomado diretamente por Cassiolato e Lastres (2003), os quais, na análise sobre aglomerados produtivos e desenvolvimento local, apontam a diferenciação entre competitividade sustentada e competitividade espúria baseada na exploração intensiva e predatória dos recursos naturais.
Noronha e Turchi (2005) enfatizam a importância da dinâmica de emprego gerada pelas micro e pequenas empresas formadoras de aglomerados produtivos, particularmente aqueles centrados em atividades de mão de obra intensiva, nos quais se verifica a expressiva informalidade como também o desrespeito de princípios de saúde e de segurança do trabalho para com os empregados.

Casarotto Filho (2005) destaca a qualidade de vida como relevante nas políticas públicas voltadas ao desenvolvimento local. $\mathrm{O}$ autor define sistema local produtivo como uma região fortemente estruturada por meio de mecanismos de integração composta de entidades representativas da região e com alta interação público-privada. Forma-se assim uma macro rede associativa, que tem como dever respeitar a cultura local e como objetivo primordial assegurar a qualidade de vida dos habitantes com ênfase no desenvolvimento local.

Verifica-se, portanto, que as análises sobre sistemas locais de produção centram a atenção na dinâmica tecnológica e nos processos de aprendizagem como elementos centrais para a obtenção de resultados econômicos (aumento da competitividade, adensamento de capacitações tecnológicas e organizacionais voltadas para a produção industrial) e sociais (geração de emprego e renda).

Buscando reduzir a lacuna existente na discussão sobre as relações envolvendo clusters industriais de empresas de menor porte e meio ambiente, propõe-se neste artigo que a abordagem da produção mais limpa $(\mathrm{P}+\mathrm{L})$, baseada na compatibilidade entre melhorias ambientais e ganhos econômicos, constitui uma alternativa a ser apreciada.

Fresner (2004) identifica como elementos inibidores da difusão da $\mathrm{P}+\mathrm{L}$ na indústria a não familiaridade das empresas com o conceito, particularmente as de menor porte e, quando o conceito é conhecido, a comunicação e o entendimento dos benefícios comerciais que podem ser obtidos são inadequados. Além disso, a implantação da $\mathrm{P}+\mathrm{L}$ requer mudança de atitude, gestão ambiental responsável e avaliação de opções tecnológicas. Khan (2008) menciona a P + L como ferramenta que auxilia empresas a melhorarem o desempenho ambiental e reduzir riscos para seus empregados.

Ainda de acordo com Fresner (2004), estudos realizados analisando experiências de gestão ambiental em empresas de menor porte têm evidenciado que o ponto central de qualquer metodologia para implantação da $\mathrm{P}+\mathrm{L}$ consiste em identificar boas opções para aumentar a eficiência no uso de materiais, água e energia.

A P + Lé tida como ferramenta particularmente atrativa para micro e pequenas empresas de países em desenvolvimento, podendo gerar resultados econômicos e ambientais favoráveis. Mas tais empresas enfrentam restrições atitudinais, organizacionais, técnicas e econômicas para a implantação da $\mathrm{P}+\mathrm{L}$, necessitando de suporte de organismos públicos e privados para superá-las (FRIJNS; VAN VLIET, 1999).

No Brasil, estudos elaborados pelo Ministério do Desenvolvimento, Indústria e Comércio Exterior e apresentados no Fórum Permanente das Microempresas e 
Empresas de Pequeno Porte (EPP) identificam, dentre os fatores que dificultam o acesso das microempresas e das empresas de pequeno porte (EPP) a recursos para desenvolvimento tecnológico e inovação, a ausência de sistemas de gestão ambiental, de ferramentas destinadas ao controle, monitoramento, destinação final, redução, reaproveitamento e reciclagem dos resíduos gerados nos processos industriais e ausência de programas de produção mais limpa por meio dos quais se produz mais (produtos) com menos (matérias-primas, insumos e resíduos) (MDIC, 2007).

Metodologia desenvolvida por Suzigan et al. (2003), para mapear tipos básicos de sistema local de produção, classificou o aglomerado das empresas de joias de São José do Rio Preto como um sistema produtivo importante para a região, representando um "vetor de desenvolvimento local". Segundo os mesmos autores, os aglomerados classificados na categoria de "vetor de desenvolvimento local" são aqueles para os quais a política de desenvolvimento está mais habilitada. Estes arranjos já superaram o estágio embrionário, não enfrentando as dificuldades inerentes aos aglomerados que representam os núcleos de desenvolvimento setorial-regional que precisam, para sobreviver, desbravar terrenos e, possivelmente, corrigir trajetórias. Os aglomerados classificados como vetores de desenvolvimento local, a certa distância daqueles classificados como núcleos de desenvolvimento setorial-regional, podem evitar a repetição de erros e identificar mais facilmente novas oportunidades.

Tal análise aponta e reconhece a importância dos aglomerados que se destacam pela inserção no sistema produtivo da região na qual estão localizados, bem como pelas possibilidades que colocam para a implantação de políticas de promoção de SLP. Assim sendo, no presente artigo procura-se identificar oportunidades para implantação da P + L no Polo Joalheiro de São José do Rio Preto, no escopo de políticas e ações destinadas ao desenvolvimento da competitividade de aglomerações industriais.

\section{Metodologia de pesquisa}

Tendo em conta a escassez verificada nas abordagens teóricas e nas análises sobre a definição e implantação de políticas para o desenvolvimento de sistemas locais de produção quanto à incorporação de questões relacionadas à dimensão ambiental, o presente trabalho constitui uma pesquisa qualitativa de caráter exploratório.

Para o desenvolvimento da pesquisa empírica, a escolha recaiu sobre o polo joalheiro de São José do Rio Preto por este ter sido selecionado para o desenvolvimento de um projeto de competitividade executado pelo Serviço Brasileiro de Apoio às Micro e Pequenas Empresas (SEBRAE). O referido projeto esteve inserido nas ações do Programa Competitividade Regional, da Federação das Indústrias do Estado de São Paulo (FIESP), e definiu como objetivo geral potencializar vocações de aglomerados regionais aumentando a produtividade e a competitividade das empresas, especialmente das micro e pequenas, promovendo a relação institucional entre as empresas e as organizações locais, estaduais e federais de apoio às empresas.

Em novembro de 2002, a FIESP selecionou o Polo Joalheiro de São José do Rio Preto, segundo maior polo joalheiro do Estado de São Paulo em confecção de joias em ouro e sendo composto por 150 empresas, para a implantação de ações focadas na promoção do arranjo produtivo local (IBGM, 2005). A necessidade de ações para o desenvolvimento do polo foi justificada por haver forte crescimento da demanda (nacional e externa), recursos naturais disponíveis no País, estrutura do setor dominada por micro e pequenas empresas e forte potencial de crescimento do polo (SEBRAE, 2003).

Desde então, o polo tem sido beneficiário do projeto piloto "Competitividade do Setor de Joias do Polo de São José do Rio Preto", resultado de uma ação conjunta envolvendo a FIESP, o Centro das Indústrias do Estado de São Paulo (CIESP), a Confederação Nacional das Indústrias (CNI), a Associação dos Joalheiros e Relojoeiros do Noroeste Paulista (AJORESP), o Serviço Brasileiro de Apoio às Micro e Pequenas Empresas (SEBRAE-SP), o Instituto Brasileiro de Gemas e Metais Preciosos (IBGM), o Sindicato da Indústria Joalheira do Estado de São Paulo (SINDIJÓIAS), o Serviço Nacional de Aprendizagem Industrial (SENAI), o Centro São Paulo de Design (CSPD) e o Núcleo de Design de São José do Rio Preto. O objetivo do projeto de competitividade é fortalecer o polo joalheiro para que as empresas tornem-se competitivas no mundo globalizado (IBGM, 2002).

Com a implementação do projeto piloto, o polo tornou-se referência junto ao Banco Nacional de Desenvolvimento Econômico e Social (BNDES) como sendo o primeiro case a solicitar uma linha de crédito específica para construção de condomínios industriais, e constituir um dos cinco polos estudados e apoiados pelo Fórum de Competitividade de Joias e Gemas do Ministério do Desenvolvimento, Indústria e Comércio Exterior (MDIC), também sendo considerado como case de sucesso na publicação do caderno de Políticas e Ações para a Cadeia Produtiva de Gemas e Joias do IBGM (2005).

A execução do projeto piloto "Competitividade do Setor de Joias do Polo de São José do Rio Preto" conta com três fases. A primeira fase, lançada em 21 de novembro de 2002, visou o incremento da produtividade, o aumento das vendas e o fortalecimento do polo por meio da implementação de ações nas áreas de gestão empresarial, design, produção, tecnologia, marketing e vendas. A segunda fase, lançada em 05 de maio de 2004 e com duração de 18 meses, colocou como objetivos apresentar as joias do polo de São José do Rio Preto para o mercado internacional; adensar a cadeia produtiva; gerar condições para o incremento contínuo da competitividade e tornar o polo uma referência no mercado mundial de joias. Nessa segunda fase de execução do projeto, 
a difusão dos conceitos de gestão ambiental e $\mathrm{P}+\mathrm{L}$, com a finalidade de reduzir desperdícios verificados no processo produtivo, figurou entre as metas a serem alcançadas (FIESP, s.d.). A terceira fase, com início previsto para o segundo semestre de 2007, porém sem previsão para o término, estabeleceu dentre o conjunto das ações previstas, sensibilização para preservação ambiental e tratamento de resíduos (FIESP, 2007).

A pesquisa de campo foi conduzida, no período de janeiro a maio de 2007, em nove de um universo de 15 empresas identificadas e contatadas que atenderam ao critério de seleção estabelecido na pesquisa, qual seja: ter participado das duas fases já concluídas do projeto de competitividade. Com relação às empresas contatadas, nas quais não foi possível conduzir a pesquisa, duas delas encerraram suas atividades, uma é fabricante de bijuteria, não se enquadrando no recorte da pesquisa, e três empresas não forneceram as informações. O conjunto de empresas no qual foi realizado o levantamento de dados é composta por três pequenas empresas e seis micro empresas. Para estratificar as empresas industriais, segundo o tamanho, adotou-se como critério o número de pessoas ocupadas, com base na classificação do SEBRAE e também utilizada pelo Ministério do Trabalho e Emprego (MTE) que associa a micro empresa à faixa de 1 a 19 pessoas ocupadas; a pequena empresa, de 20 a 99 pessoas; a média empresa, de 100 a 499; e considera como grande empresa aquela com 500 ou mais pessoas ocupadas (SEBRAE, 2003).

A definição das variáveis para a coleta de dados empíricos e a identificação de evidências que contribuam para o conhecimento da dinâmica tecnológica e da inovação no polo joalheiro, bem como das oportunidades para implantação da P + L, foram feitas considerando: 1) um conceito abrangente de inovação, em consonância com os levantamentos feitos no Brasil (IBGE, 2002) e no exterior (Manual de Oslo/OCDE, 2005). A inovação é a implementação de mudanças referentes a novos produtos, novos atributos em produtos existentes, novos processos, novas formas de organização de trabalho realizadas pela empresa que seja nova para ela ou para o mercado. A inovação está associada à criação de vantagens competitivas e à elevação dos padrões competitivos da indústria; 2) a abordagem da $\mathrm{P}+\mathrm{L}$ destacando benefícios econômicos, ambientais e de saúde e segurança ocupacional.

Com relação aos instrumentos de coleta de dados, houve a aplicação presencial de questionário semiestruturado, respondido pelos proprietários ou sócios proprietários das empresas participantes das duas fases concluídas do projeto piloto, as fases 1 e 2, no período da realização da pesquisa de campo. Os dados coletados se referem ao período 2002-2006. Os aspectos considerados no formulário das entrevistas foram: caracterização do processo produtivo, esforços de atualização tecnológica e meio ambiente.

\section{Processo produtivo na indústria de joias e identificação de aspectos ambientais}

As empresas do setor joalheiro se caracterizam por utilizar como principais matérias-primas recursos naturais não renováveis (metais nobres e gemas preciosas). Durante o seu processo produtivo, existe o consumo relativamente importante de produtos químicos relacionados à emissão de efluentes líquidos e gasosos e à geração de resíduos sólidos.

O processo produtivo de joias diz respeito a um conjunto de atividades interligadas e ordenadas, tendo como objetivo alcançar a produção desejada. Não existe um processo único padronizado/uniformizado para o setor, pois o próprio estágio em que se encontra a indústria define o processo e a tecnologia empregada. Os processos utilizados no setor joalheiro podem ser classificados como artesanal, semiautomático e automático. Uma mesma empresa, dependendo do seu grau de desenvolvimento tecnológico, pode adotar os três tipos de processos de acordo com a etapa a ser realizada e também da peça a ser fabricada.

A classificação "artesanal" é devida à utilização de mão de obra em determinadas etapas do processo produtivo. Dependendo do tipo da joia (joia exclusiva) o processo é totalmente artesanal, ou seja, a peça única é confeccionada por um ourives.

Já a classificação "semiautomático" implica a utilização de máquinas semiautomáticas em alguma etapa do processo produtivo necessitando de um operador para realizar as funções, ou seja, comandar/acionar a máquina. Exemplificando: para derreter o ouro em uma fundidora e injetá-lo no cilindro que contém os modelos das joias em gesso, é necessário que o operador dê o comando para a máquina.

A classificação "automático" significa que em alguma etapa do processo produtivo as máquinas precisam apenas de um operador que as programe. Complementando o exemplo citado acima, num processo automático, a fundidora derrete o ouro e em seguida injeta-o, com a pressão necessária, no cilindro que contém os modelos das joias em gesso, sem a interferência do operador, bastando apenas ser programada no início do processo.

Os três processos produtivos mais empregados na produção joalheira são: o de fundição por cera perdida, laminação/estamparia e trefilação/correntaria.

Nas empresas joalheiras do Polo de São José do Rio Preto prevalece o processo de fundição por cera perdida devido à sua versatilidade e rapidez (IBGM, 2002). Na Figura 1, com base na pesquisa realizada nas empresas entrevistadas, encontram-se sintetizadas as etapas do processo produtivo com a identificação dos respectivos aspectos ambientais.

Uma vez identificados os aspectos ambientais, cabe ressaltar a importância de incorporar esse tema na promoção 


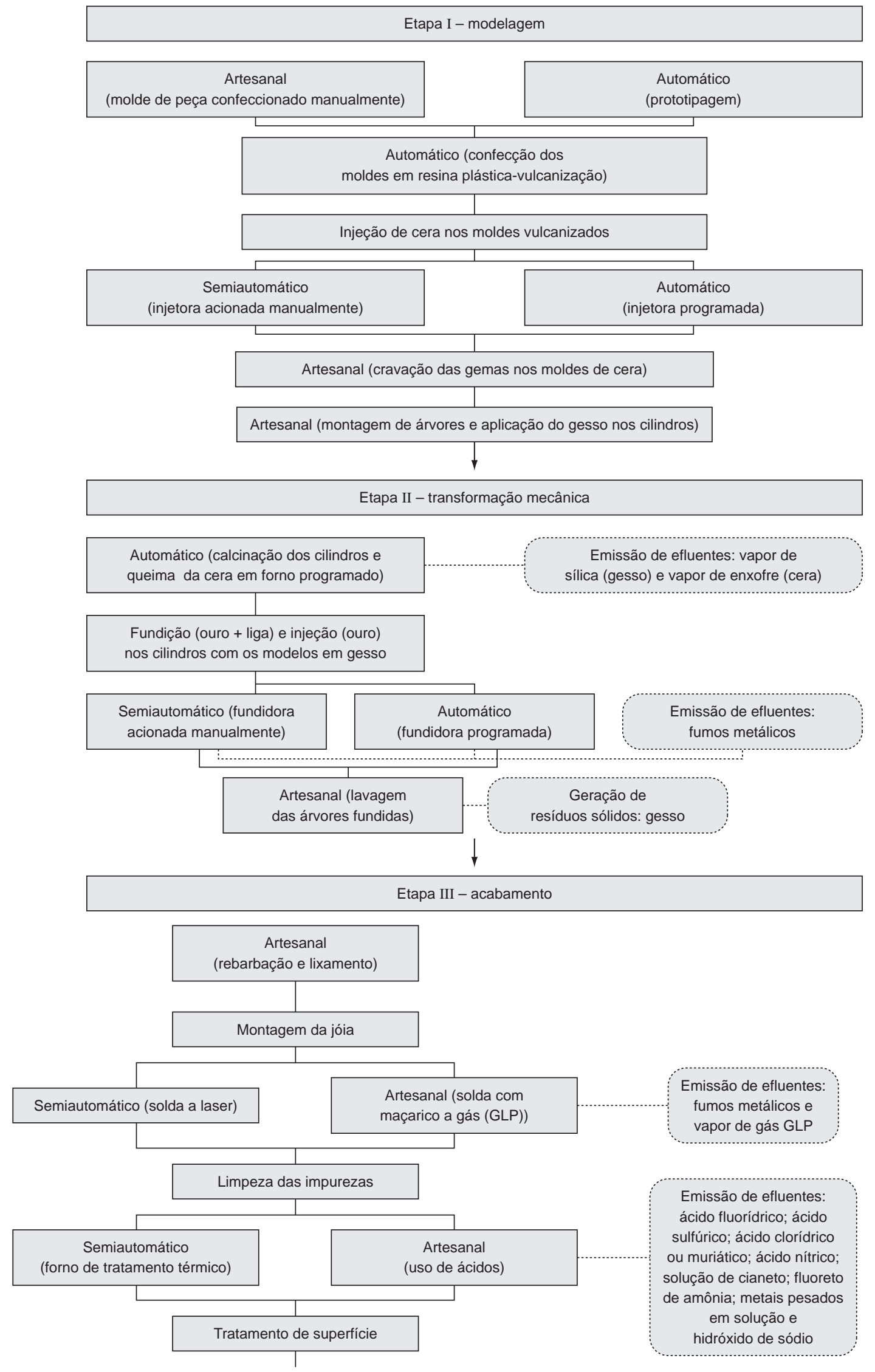

Figura 1. Processo Produtivo de Joias e Aspectos Ambientais - Fundição por Cera Perdida. Fonte: Elaboração própria a partir da pesquisa de campo (2007). 


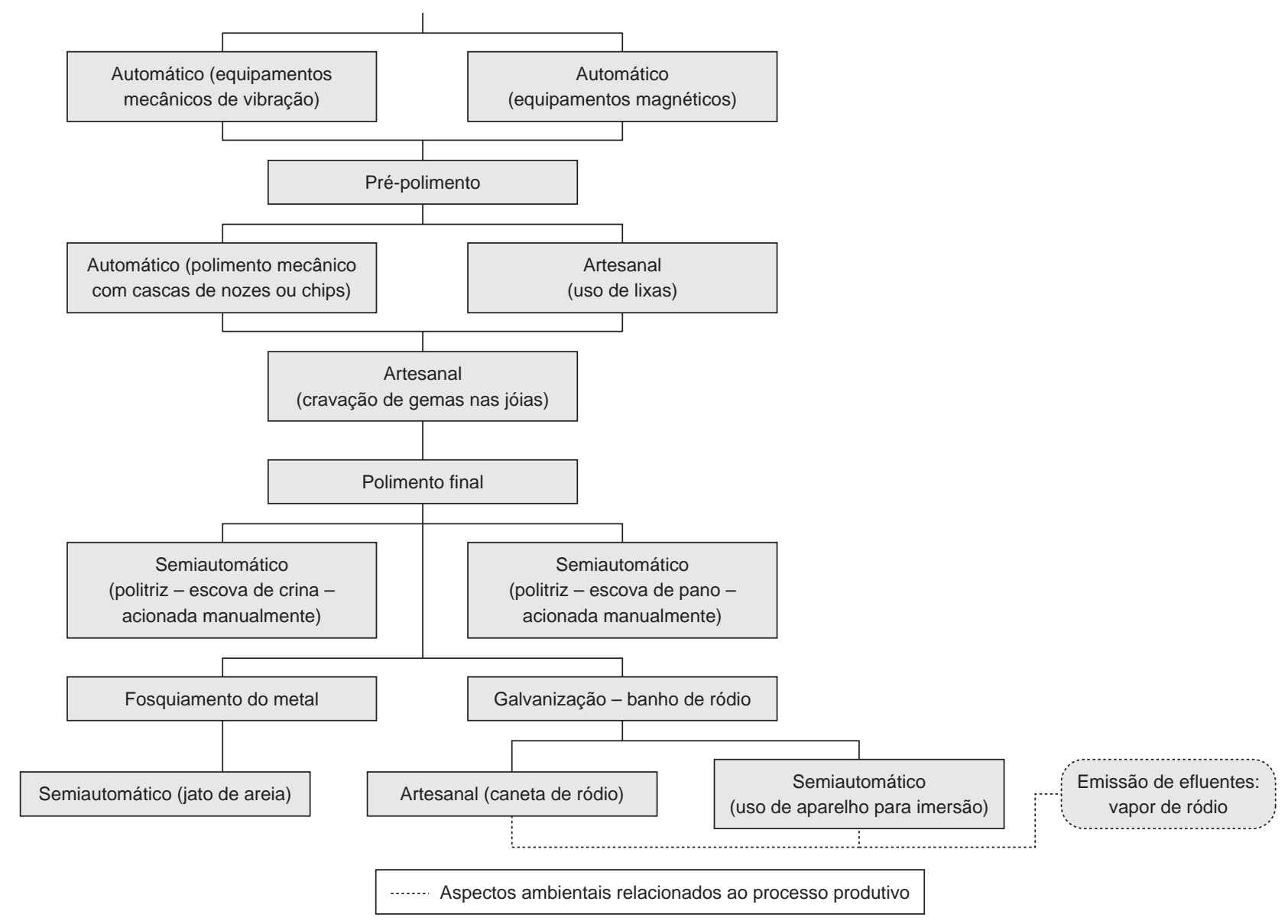

Figura 1. Continuação...

de sistemas locais de produção, considerando também as necessidades em termos de aporte de tecnologia. Uma possibilidade é buscar melhorias no desempenho ambiental das empresas considerando o conceito e as práticas de $\mathrm{P}+\mathrm{L}$ tendo em vista a obtenção de benefícios gerados com o concomitante aumento da eficiência dos processos produtivos.

\section{Oportunidades para implantação da produção mais limpa no polo joalheiro de São José do Rio Preto}

A inadequação tecnológica figura entre as principais dificuldades para o fortalecimento e expansão da indústria de joias de ouro, principalmente no que diz respeito à capacitação técnica e tecnológica das empresas, ao aumento de padrões de produtividade e à melhoria da competitividade. Os diversos processos produtivos são utilizados com distintos graus de eficiência, causados pela boa ou má utilização da tecnologia disponível, das máquinas, dos equipamentos e das ferramentas empregadas. Há dificuldades na manutenção e utilização dos equipamentos e também na aquisição de matérias-primas e insumos de melhor qualidade (IBGM, 2005).
Oliveira Filho (2001) define a P + L como uma estratégia tecnológica de caráter permanente que exige ações contínuas e integradas para conservar energia e matéria-prima, substituir recursos não renováveis por renováveis e eliminar substâncias tóxicas, reduzindo desperdícios e a poluição resultante dos produtos e processos produtivos.

Essa definição pode explicitar uma visão restritiva da $\mathrm{P}+\mathrm{L}$, cabendo então esclarecer que uma análise comparativa entre tecnologias de fim de tubo e a produção mais limpa mostra que, enquanto nas tecnologias de fim de tubo a solução para problemas ambientais é buscada de uma perspectiva tecnológica, na $\mathrm{P}+\mathrm{L}$ os problemas ambientais devem ser resolvidos em todos os níveis e em todos os campos. Compatível com uma visão mais abrangente, a $\mathrm{P}+\mathrm{L}$ é um conceito internacionalmente reconhecido como uma abordagem moderna e eficaz de se analisar e gerenciar os recursos de produção, dentro de uma visão preventiva e proativa quanto à geração de resíduos e desperdícios (CNTL, 2003 apud SILVA; MEDEIROS, 2006). Tais visões diferenciadas evidenciam, portanto, dois enfoques possíveis sobre a $\mathrm{P}+\mathrm{L}$, sendo o primeiro enfoque mais restritivo, focado na prevenção de problemas ambientais decorrentes das atividades das empresas; e o segundo, um enfoque de caráter abrangente relacionado à $\mathrm{P}+\mathrm{L}$ como a 
aplicação continuada de uma estratégia ambiental preventiva e integrada aos processos, produtos e serviços. (UNIDO/ UNEP, 1995).

Isto posto, a utilidade da definição de $\mathrm{P}+\mathrm{L}$ de Oliveira Filho (2001) para o presente trabalho, que considera os esforços de atualização tecnológica em um grupo de empresas do Polo Joalheiro de São José de Rio Preto, está justamente em destacar o papel que a inovação tecnológica de produto e de processo pode ter na solução de problemas ambientais.

Segundo a UNEP (2002), a experiência desenvolvida com micro e pequenas empresas pertencentes a países em desenvolvimento e que investiram menos de US\$ 3 mil em $\mathrm{P}+\mathrm{L}$ conseguiu reduzir a carga de poluição em mais de $25 \%$ além de recuperar os investimentos, em muitos casos, em menos de seis meses.

Para implementar a P + L, as ações deverão estar sempre voltadas para três benefícios básicos, de acordo com o Centro Nacional de Tecnologias Limpas no Brasil (CNTL, 2000):

- Benefício ambiental (eliminação ou redução de resíduos e emissões; atender às exigências da legislação ambiental, etc.);

- Benefício de saúde e segurança ocupacional (eliminar ou reduzir substancialmente os riscos à saúde e segurança dos empregados); e

- Benefício econômico (reduzir os custos com compra de matéria-prima e insumos; e com a disposição final de resíduos e produtos, etc.).

O conceito de $\mathrm{P}+\mathrm{L}$ teve sua metodologia desenvolvida pela United Nations Industrial Development Organization (UNIDO) e é a base do programa de prevenção proposto pela própria UNIDO e pela United Nations Environment Programme (UNEP) para nações em desenvolvimento, com a seguinte abordagem:

\begin{abstract}
Produção mais Limpa é a aplicação contínua de uma estratégia ambiental preventiva e integrada, nos processos produtivos, nos produtos e nos serviços, para reduzir os riscos relevantes aos seres humanos $\mathrm{e}$ ao ambiente natural. São ajustes no processo produtivo que permitem a redução da emissão/geração de resíduos diversos, podendo ser feitas desde pequenas reparações no modelo existente até a aquisição de novas tecnologias (simples e/ou complexas) (PROGRAMA DAS NAÇÕES UNIDAS PARA O MEIO AMBIENTE - UNEP, 1989).
\end{abstract}

A abordagem da $\mathrm{P}+\mathrm{L}$, baseada na compatibilidade entre melhorias ambientais e ganhos econômicos, torna-se neste contexto uma alternativa a ser considerada. A implementação da $\mathrm{P}+\mathrm{L}$ implica mudanças no processo produtivo com incorporação de tecnologias que permitam aumentar a eficiência no uso de matérias primas, água, energia e reduzir os riscos para o homem e o meio ambiente (CNTL, 2000).
Nos seus esforços de atualização tecnológica, as empresas pertencentes ao polo joalheiro de São José do Rio Preto têm adotado mudanças no processo produtivo que podem ser sistematizadas e analisadas a partir da implantação da abordagem e da metodologia propostas pela $\mathrm{P}+\mathrm{L}$.

De acordo com a pesquisa de campo, verifica-se que as inovações no polo joalheiro estão vinculadas, sobretudo, às melhorias no processo produtivo com a incorporação de insumos, máquinas e equipamentos decorrentes de investimentos em atualização tecnológica.

Com vistas a melhorar o desempenho da produção, a busca de atualização tecnológica redundou na compra de fundidoras, soldadoras a laser, máquinas de prototipagem, injetoras de cera e fornos de tratamento térmico e de calcinação.

Há também melhorias de processo a partir da utilização de insumos químicos, utilizados em menor quantidade, que contribuem para a redução do custo final das peças.

É a partir desses imperativos que a busca de atualização tecnológica tem-se colocado como diferencial competitivo a ser explorado.

Esse aspecto é abordado a seguir, analisando os dados da pesquisa, tendo como referência a abordagem da $\mathrm{P}+\mathrm{L}$.

Utilizando os Níveis de Aplicação da Produção mais Limpa (CNTL, 2000) e aplicando-os na análise das modificações no processo produtivo no polo joalheiro, a Figura 2 mostra os níveis de aplicação da $\mathrm{P}+\mathrm{L}$ identificados:

Os esforços compatíveis com a minimização de resíduos, efluentes e emissões, identificados no polo joalheiro de São José do Rio Preto, apontaram resultados que permitiram a redução na fonte (nível de aplicação1) devido à modificação no processo produtivo, por meio do uso de técnicas de housekeeping; substituição de matérias-primas e/ou materiais auxiliares e de modificação tecnológica, apresentados no Quadro 1.

Com relação à reciclagem interna (nível de aplicação 2), ou seja, o processo de recuperação de matérias-primas, materiais auxiliares e insumos realizados dentro da planta industrial, para serem utilizados novamente com o mesmo propósito (CNTL, 2000), constatou-se que, mesmo não sendo uma prática amplamente disseminada, são adotadas técnicas de purificação aplicada a resíduos e efluentes com o objetivo de recuperar perdas da principal matéria-prima (ouro).

No tocante à adoção de medidas de reciclagem externa (nível de aplicação 3), prática amplamente disseminada, recorre-se à contratação de empresas recuperadoras/ purificadoras, enviando os ácidos, cianuretos e materiais recolhidos (através de sucção, aspiração, varredura e decantação) para posterior purificação e recuperação das perdas de ouro.

A adoção generalizada de controle de perdas é explicada pelo alto custo da matéria-prima, o ouro, sendo essencial para tornar os produtos competitivos. 


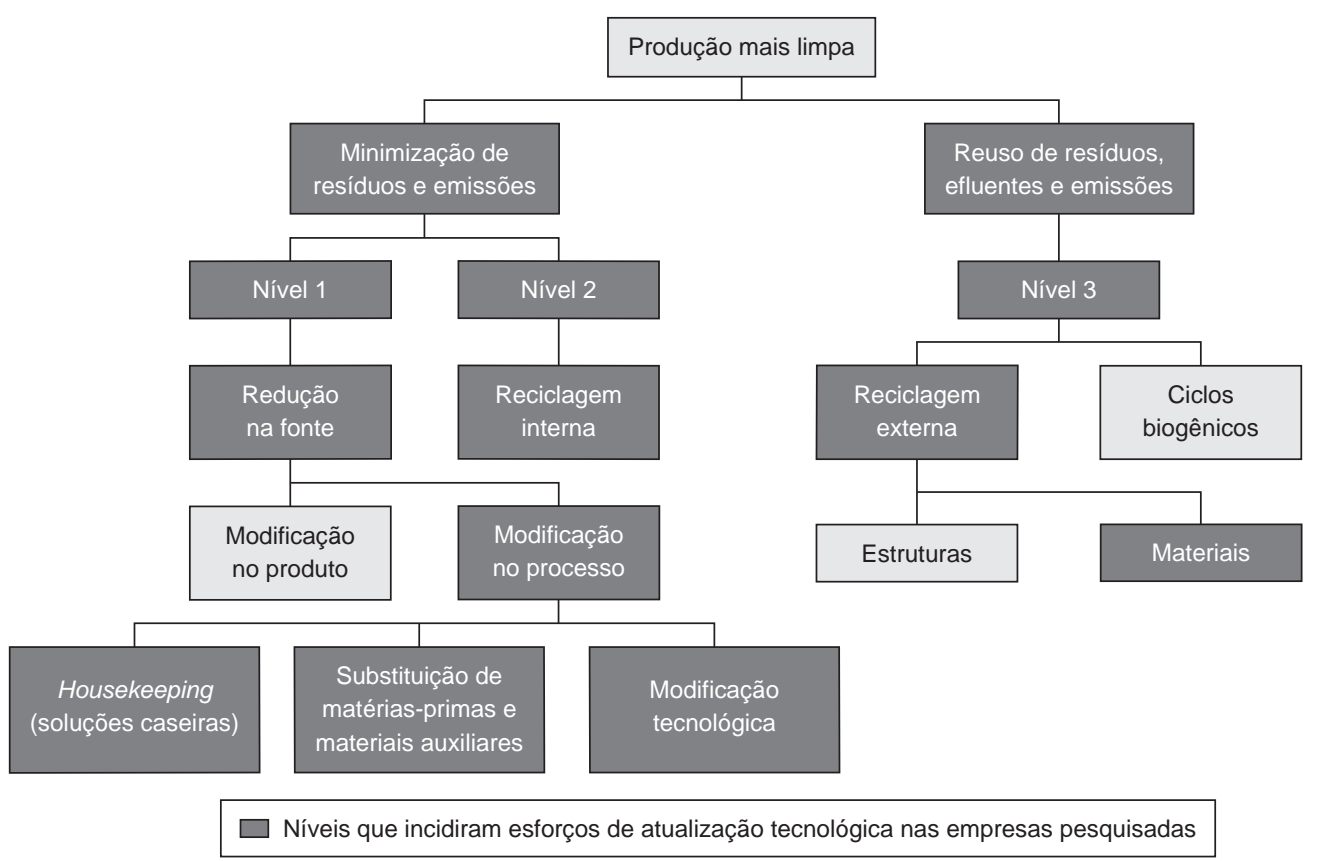

Figura 2. Atualização tecnológica segundo níveis de aplicação da produção mais limpa. Fonte: Dados da pesquisa, com base em CNTL (2000).

Quadro 1. Modificações no processo produtivo.

\begin{tabular}{|c|c|}
\hline Modificações & Ações \\
\hline $\begin{array}{l}\text { Housekeeping - alterações nos processos inter- } \\
\text { nos usando criatividade, a um baixo custo, sem } \\
\text { exigência de alterações tecnológicas significa- } \\
\text { tivas e que atendam às práticas de prevenção ou } \\
\text { minimização de resíduos, efluentes e emissões; } \\
\text { operação adequada de equipamentos e melhor } \\
\text { organização interna. }\end{array}$ & $\begin{array}{l}\text { - Mudança no processo produtivo da empresa - implantação de maior } \\
\text { controle da produção; } \\
\text { - } \quad \text { Reorganização dos intervalos de limpeza; } \\
\text { - Instalação de filtros para absorção de pó de ouro; retenção de } \\
\text { fumos metálicos e fumos provenientes da queima de cera; } \\
\text { - Instalação de caixas de contenção para reter resíduos de gesso; } \\
\text { - Instalação de caixas de decantação; } \\
\text { - Uso de máquina de limpeza com pressão a jato; } \\
\text { - Instalação de BIP (sinal acústico emitido por aparelho) para evitar } \\
\text { o recozimento do ouro + liga, diminuindo a emissão de fumos } \\
\text { metálicos; } \\
\text { - Colocação de tapetes para reter o pó de ouro. }\end{array}$ \\
\hline $\begin{array}{l}\text { Substituição de matérias-primas e/ou materiais } \\
\text { auxiliares - substituição de materiais toxicolo- } \\
\text { gicamente importantes, que podem afetar a saúde } \\
\text { e a segurança do trabalhador e obrigam à utili- } \\
\text { zação de equipamentos de proteção individual } \\
\text { (EPIs); que geram resíduos, efluentes e emissões } \\
\text { perigosos ou não inertes, que necessitam de } \\
\text { controle para evitar impactos negativos ao meio } \\
\text { ambiente. }\end{array}$ & $\begin{array}{l}\text { - Substituição do ácido sulfúrico pelo ácido sulfônico; } \\
\text { - Substituição da amônia por detergentes menos tóxicos; e } \\
\text { - Substituição de cianuretos pelo forno de tratamento térmico. }\end{array}$ \\
\hline $\begin{array}{l}\text { Modificação tecnológica-são orientadas para as } \\
\text { modificações de processo e de equipamento para } \\
\text { reduzir resíduos, efluentes e emissões no sistema } \\
\text { de produção. Podem variar desde mudanças } \\
\text { simples, que podem ser implementadas num } \\
\text { curto período, até mudanças complexas e } \\
\text { onerosas, como substituição completa de um } \\
\text { processo. }\end{array}$ & $\begin{array}{l}\text { - Aquisição de máquina de fundição moderna com menor poder de } \\
\text { oxidação e que permita fazer cravação das gemas nos moldes em } \\
\text { cera; } \\
\text { - Aquisição de forno de tratamento térmico utilizado para desoxidar } \\
\text { o ouro; } \\
\text { - Aquisição de máquina de solda a laser; } \\
\text { - Aquisição de maçarico a hidrogênio; e } \\
\text { - Aquisição de máquina de polimento mecânico. }\end{array}$ \\
\hline
\end{tabular}

Fonte: Elaboração própria. 
Melhorias ambientais foram observadas devido às medidas adotadas pelas empresas pesquisadas, conforme demonstra o Quadro 2.

Verifica-se, portanto, que as mudanças no processo produtivo, em particular aquelas ligadas à atualização tecnológica, apresentam resultados compatíveis com a abordagem e as práticas de $\mathrm{P}+\mathrm{L}$, tendo em vista a obtenção de benefícios gerados a partir do aumento da eficiência dos processos e da redução no consumo de matérias-primas e de energia, bem como na geração de resíduos e nas emissões.

A análise das modificações ocorridas, com base na abordagem da $\mathrm{P}+\mathrm{L}$, auxilia na identificação de oportunidades para promover melhorias no desempenho ambiental juntamente com a eficiência produtiva.

Observou-se que, independente de incentivos e ações externas ou de exigências dos canais de distribuição e dos consumidores, a atualização tecnológica em curso no polo, mesmo que de modo não deliberado para essa finalidade, tem gerado melhorias ambientais.

\section{Conclusão}

Apesar dos sistemas locais de produção (SLP) atualmente serem foco nas esferas internacional e nacional, de políticas e ações voltadas ao desenvolvimento da competitividade da indústria local com base na dinamização de vantagens de aglomeração, as análises e diagnósticos que se dedicam ao estudo desses SLP não oferecem maiores desdobramentos analíticos para a discussão da variável ambiental.

O estudo dos SLP, focalizando a inovação tecnológica com base na abordagem evolucionista, permite internalizar a variável ambiental, colocando-a sob uma nova perspectiva, uma vez que a concepção da natureza dos problemas ambientais é considerada enquanto produto endógeno da dinâmica evolutiva econômica e tecnológica.

No caso estudado observou-se que, independente de incentivos, de ações externas ou exigências dos canais de distribuição e dos consumidores que enfatizem a variável ambiental, as empresas estão investindo em atualização tecnológica, pela necessidade de permanecerem no mercado altamente competitivo.

O desenvolvimento tecnológico do setor de joias é fortemente calcado em estratégias voltadas à melhoria da capacidade produtiva. Observa-se que a forma mais importante de inovação está relacionada a melhorias no processo produtivo.

Assim sendo, com vistas a aumentar a eficiência da produção, a busca de atualização tecnológica do conjunto de empresas pesquisadas deu-se por meio da aquisição de fundidoras, soldadoras a laser, máquinas de prototipagem, injetoras de cera e fornos de tratamento térmico e de calcinação, bem como da utilização de novos insumos químicos.

O polo joalheiro de São José do Rio Preto tem uma importância significativa para a economia regional e nacional,

Quadro 2. Melhorias ambientais.

\begin{tabular}{|c|c|}
\hline Modificação no processo produtivo & Resultados \\
\hline $\begin{array}{l}\text { Aquisição de máquina de fundição moderna; mudança do padrão } \\
\text { bifásico por trifásico; reforma das instalações e colocação de bips } \\
\text { para evitar o recozimento do ouro + liga. }\end{array}$ & $\begin{array}{l}\text { Redução do consumo de energia elétrica/quantidade de } \\
\text { ouro manufaturada. }\end{array}$ \\
\hline $\begin{array}{l}\text { Instalação de caixa d'água única; utilização de máquina de lim- } \\
\text { peza com pressão a jato e uso de máquina de quebrar o gesso } \\
\text { utilizado nos moldes. }\end{array}$ & $\begin{array}{l}\text { Redução no consumo de água/quantidade de ouro manu- } \\
\text { faturada. }\end{array}$ \\
\hline $\begin{array}{l}\text { Aquisição de máquina fundidora moderna; máquina de polimento } \\
\text { mecânico; aquisição de forno de tratamento térmico; instalação } \\
\text { de caixas de decantação; colocação de tapetes e instalação de } \\
\text { filtros para reter o pó de ouro; limpeza diária e maior controle da } \\
\text { produção. }\end{array}$ & $\begin{array}{l}\text { Redução de perdas e desperdício no uso de matéria-prima } \\
\text { (ouro). }\end{array}$ \\
\hline $\begin{array}{l}\text { Aquisição de máquina de solda a laser; implantação de tubulações } \\
\text { externas conforme normas determinadas pelo Corpo de Bombeiros; } \\
\text { novas instalações que permitem o uso do gás acondicionado em } \\
\text { embalagem industrial e uso de maçarico de hidrogênio. }\end{array}$ & $\begin{array}{l}\text { Redução do consumo de gás (GLP)/quantidade de ouro } \\
\text { manufaturada. }\end{array}$ \\
\hline $\begin{array}{l}\text { Aquisição de máquina de polimento mecânico; de forno de trata- } \\
\text { mento térmico e máquina de solda a laser; uso de máquina "quebra } \\
\text { gesso"; instalação de filtros à base de água para reter os fumos } \\
\text { metálicos e substituição da amônia e ácido sulfúrico. }\end{array}$ & $\begin{array}{l}\text { Redução da geração e disposição de resíduos sólidos (gesso, } \\
\text { cera); da emissão e tratamento de efluentes líquidos (ácidos); } \\
\text { da emissão gasosa (fumos metálicos) originados no processo } \\
\text { produtivo. }\end{array}$ \\
\hline $\begin{array}{l}\text { Aquisição de máquina fundidora moderna (oxida menos as peças); } \\
\text { aquisição de forno de tratamento térmico; substituição do ácido sul- } \\
\text { fúrico pelo sulfônico e da amônia por detergentes menos tóxicos. }\end{array}$ & $\begin{array}{l}\text { Redução do consumo de insumos químicos/quantidade } \\
\text { de ouro manufaturada; substituição por insumos menos } \\
\text { agressivos ambientalmente; melhorias nas práticas e pro- } \\
\text { cedimentos para manuseio de insumos químicos. }\end{array}$ \\
\hline
\end{tabular}

Fonte: Elaboração própria. 
pois, no entorno das empresas de joias, encontram-se vários fornecedores que contribuem para o fortalecimento do aglomerado, sendo designers (autônomos); fornecedores de ouro e gemas com escritórios de representação instalados na cidade; empresas de liga ou pré-ligas, com destaque para a empresa local que desenvolveu um tipo de liga que é muito utilizada no polo devido à sua qualidade e à assistência técnica; empresas representantes de máquinas e equipamentos para o setor; empresas locais de máquinas e equipamentos que desenvolvem produtos de acordo com a necessidade das empresas (forno de tratamento térmico e máquina de prototipagem rápida); de purificação; distribuidoras de títulos (empresas autorizadas para venda de ouro) e fornituras (empresas que vendem produtos exclusivos para joalheria).

Os representantes dos fornecedores de máquinas e equipamentos importados e fornecedores de máquinas e equipamentos nacionais encontram-se, na maior parte, nas cidades de São Paulo/SP e Belo Horizonte/MG, porém $44,45 \%$ das empresas entrevistadas citaram a cidade de São José do Rio Preto/SP e adjacências como locais onde se encontram também esses fornecedores.

Por outro lado, as empresas que adquirem insumos de fornecedores instalados em outras localidades e que são visitadas por vendedores, também acabam efetuando a compra quando identificam maior variedade de produtos e preços menores que os praticados pelos fornecedores locais.

Em função da necessidade de aumentar a competitividade, por meio de incremento dos fatores de produtividade e da eficiência coletiva, agentes locais vêm se mobilizando e estabelecendo parcerias.

As relações com fornecedores de insumos (produtos químicos), máquinas e equipamentos importados se dão por meio de revendedores autorizados. Esses fornecedores constituem a principal fonte de inovação sendo esta associada a melhorias no processo produtivo.

Por outro lado, analisando as modificações ocorridas no processo produtivo, com base na abordagem da produção mais limpa $(\mathrm{P}+\mathrm{L})$, foram identificadas oportunidades para promover melhorias no desempenho ambiental juntamente com a eficiência produtiva; para aumentar a competitividade via elevação dos níveis de produtividade e redução de custos. As modificações realizadas contribuíram para a obtenção de vários benefícios, dentre eles:

- Benefícios ambientais: redução do consumo de energia elétrica e água; do consumo de insumos químicos (substituição por insumos menos agressivos); da emissão de fumos metálicos e dos provenientes da queima da cera; da geração de resíduos sólidos (gesso e cera);

- Benefícios de saúde e segurança ocupacional: diminuição do contato dos empregados com insumos químicos utilizados no processo de fabricação das joias e vapor de gás (GLP); e

- Benefícios econômicos: redução de custos devido ao aumento da eficiência produtiva ou à redução de perdas e desperdícios no uso de insumos e matériasprimas.
A identificação dos benefícios atrelados à implantação da $\mathrm{P}+\mathrm{L}$ pode fornecer subsídios para a introdução da gestão ambiental em ações voltadas à promoção do polo, auxiliando na definição de prioridades e na identificação de problemas, de soluções possíveis e de oportunidades na área ambiental; de modo a tornar a gestão efetiva na melhoria do desempenho ambiental. Pesquisas futuras poderiam avançar na discussão buscando quantificar os benefícios obtidos ou previstos e auxiliando na definição de metas para aumentar o desempenho ambiental das empresas.

A capacidade produtiva é uma variável-chave nos setores tradicionais estando relacionada ao aproveitamento de oportunidades para aumentar a competitividade via elevação dos níveis de produtividade e redução de custos.

As ações voltadas ao incremento da competitividade do polo podem ter na incorporação da variável um elemento estratégico na promoção de SLP via desenvolvimento tecnológico e da inovação. Verificou-se que as inovações no polo joalheiro estão vinculadas, sobretudo, às melhorias no processo produtivo com a incorporação de insumos, máquinas e equipamentos decorrentes de investimentos em atualização tecnológica. Em sintonia com a literatura sobre aglomerações industriais em países em desenvolvimento, a tecnologia e a inovação colocam-se como elementos determinantes da competitividade de longo prazo do SLP. Trata-se de micro e pequenas empresas atuando em ambientes de baixo conteúdo tecnológico, para as quais a capacidade de inovação ocorre no próprio ambiente de produção ou incorporando inovações originadas em outras empresas consideradas fontes externas de inovação.

Buscando integrar a dimensão ambiental aos elementos fornecidos por esse arcabouço conceitual, a análise dos dados empíricos a partir dos níveis de aplicação da $\mathrm{P}+\mathrm{L}$, da escala de prioridades no gerenciamento de resíduos e dos resultados em termos de benefícios econômicos apontam a $\mathrm{P}+\mathrm{L}$ como alternativa a ser melhor explorada para viabilizar e sistematizar a obtenção de melhorias no desempenho ambiental das empresas do polo joalheiro.

A abordagem da $\mathrm{P}+\mathrm{L}$ é baseada na compatibilidade entre melhorias ambientais e ganhos econômicos, sendo utilizada como uma ferramenta que permite caracterizar e sintetizar oportunidades para a efetivação de melhorias ambientais em micro e pequenas empresas. A implantação da P + Lé compatível com o aproveitamento de oportunidades para a incorporação de tecnologias que permitam aumentar a eficiência no uso de matérias-primas, água, energia e reduzir impactos ambientais e riscos para os empregados.

Incorporar essa perspectiva de análise em políticas e ações de estruturação e desenvolvimento de SLP, composto na sua maioria por micro e pequenas empresas, pode vir a constituir um elemento basilar na sustentabilidade das empresas do polo em sintonia com requerimentos econômicos, sociais e ambientais do desenvolvimento. 


\title{
Potential for implantation of cleaner production in local production systems: the jewelry cluster of São José do Rio Preto
}

\begin{abstract}
Policies and actions in national and international spheres which aim to develop the local industry competition, taking as their basis the many advantages of agglomeration, have been focusing on the local production systems (LPS). Such actions and policies indicate the LPS as a vector of economic dynamism that improves local development, emphasizing the role of micro and small enterprises (MSE) which occur in an industrial agglomeration. However, the environmental dimension has thus far only received tangential treatment within the policies and actions in the promotional and structural activities mentioned above. Thus, there is a question as to how we could contemplate this dimension in order to understand and promote LPS, including the objective of preventing and reducing negative environmental impacts from the activities of these agglomerations. The article proposes to examine the opportunities for integration of environmental issues in a group of enterprises that belong to the São José do Rio Preto-SP Jewelry Cluster, which is the second largest in the State of São Paulo in manufacturing jewelers made from gold. These enterprises joined a competitiveness project undertaken by SEBRAE (Brazilian Agency for Support of Micro and Small Enterprises). The analysis adopts the cleaner production proposal $(P+L)$ as an approach and tool for environmental management, particularly suitable for smaller enterprises that are able to converge innovation efforts in order to provide alternatives for undertaking improvements in environmental performance. Qualitative exploratory research found that endeavors to update technology in the jewelry cluster analyzed with a view to cleaner production, leads to environmental, economic and occupational health and safety benefits due to the reduction in the consumption of raw materials, water and energy, as well as the reduced generation of waste and emissions. The qualitative exploratory research identified opportunities to incorporate the environmental issues in policies and actions for structuring and promoting LPS, considering specificities and the technological dynamic of the sector of micro and small enterprises.
\end{abstract}

Keywords: Cleaner production. Technological innovation. Local production systems. Cluster. Jewelry industry

\section{Referências bibliográficas}

AMARAL FILHO, J. et al. Núcleos e arranjos produtivos locais: casos do ceará. In: Proposição de políticas para a promoção de sistemas produtivos locais de MPME, set. 2002. Disponível em: <http:// www. ie.ufrj.br/redesist/Artigos/LasParcerias.pdf >. Acesso em: 02 de Fevereiro de 2005.

AMORIM, M. A.; IPIRANGA, A. S. R.; MOREIRA, V. M. C. Um modelo de tecnologia social de mobilização de arranjos produtivos locais: uma proposta de aplicabilidade. Disponível em: $<$ htpp://www.ebape.fgv.br/radma/doc/artigos/Amorin\%20et\%20 al\%20-20workshop\% 20APLs>. Acesso em: 12 de Dezembro de 2005.

BRASIL. Centro Nacional de Tecnologias Limpas do Brasil CNTL, 2000. Disponível em <http:// www.senairs.org.br/cntl>. Acesso em: 08 de Junho de 2005.

BRASIL. Ministério do Desenvolvimento, Indústria e Comércio Exterior - MDIC. Desenvolvimento tecnológico e inovação nas microempresas e empresas de pequeno porte: Fatores de influência. Fórum Permanente das Microempresas e Empresas de Pequeno Porte. Brasília, 2007.

CASAROTTO FILHO, N. Instrumentos de integração e governança em aglomerados competitivos. Disponível em: $<$ http://www. ucdb.br/coloquio/arquivos/ Casaroto.pdf >. Acesso em: $20 \mathrm{de}$ Dezembro de 2005.

CASSIOLATO, J. E.; LASTRES, H. M. M. Novas políticas na era do conhecimento: o foco em arranjos produtivos e inovativos locais, 2002. Disponível em: <http:// www. ie.ufrj.br/
redesist/Artigos/LasParcerias.pdf>. Acesso em: 02 de Fevereiro de 2005.

LASTRES, H. M. M. O foco em arranjos produtivos e inovativos de micro e pequenas empresas. In: LASTRES, H. M. M.; CASSIOLATO, J. E.; MACIEL, M. L. (Orgs.). Pequena empresa: cooperação e desenvolvimento local. Rio de Janeiro: Relume Dumará, 2003.

CLARO, P. B. O.; CLARO, D. P.; AMÂNCIO, R. Entendendo o conceito de sustentabilidade nas organizações. Revista de Administração, v. 43, n. 4, p. 289-3000, out./dez. 2008.

DINIZ, C. C. Repensando a questão regional brasileira: tendências, desafios e caminhos. In: SEMINÁRIO DESENVOLVIMENTO EM DEBATE: Novos Rumos do Desenvolvimento no Mundo. Rio de Janeiro: BNDES, Setembro 2002.

FEDERAÇÃO DAS INDÚSTRIAS DO ESTADO DE SÃO PAULO - FIESP. Relatório de Encerramento APL $2^{\text {a }}$ fase: Pólo Joalheiro de São José do Rio Preto. (dados não publicados).

Escopo do projeto arranjo produtivo local: Programa competitividade de jóias de São José do Rio Preto. 2007. 2 p. (dados não publicados).

FRESNER, J. Small and medium sized enterprises and experiences with environmental management. Journal of Cleaner Production, v. 12, p. 545-547, 2004.

FRIJNS, J.; Van VLIET, B. Small-Scale Industry and Cleaner Production Strategies. World Development, v. 27, n. 6, p. 967-983, 1999. 
HADDAD, P. R. A organização dos sistemas produtivos locais como prática de desenvolvimento endógeno. In: SEMINÁRIO DE MICROFINANÇAS, Rio de Janeiro, 2002. Disponível em: <http://proder.sebrae-sc.com.br/formularios/ Artigo_Paulo\%20 Haddad.pdf. Acesso em: 08 de Abril de 2006.

INSTITUTO BRASILEIRO DE GEOGRAFIA E ESTATÍSTICA - IBGE. Pesquisa industrial anual: Inovação tecnológica Pintec 2000. Rio de Janeiro, 2002.

INSTITUTO BRASILEIRO DE GEMAS E METAIS PRECIOSOS - IBGM. Competitividade do Setor de Jóias do Pólo de São José do Rio Preto. Convênio CNI/SEBRAE 2000-2002-05-7. São Paulo, 2002.

Políticas e Ações para a Cadeia Produtiva de Gemas e Jóias. HENRIQUES, H. S.; SOARES, M. M. (Coords.). Brasília: Brisa, 2005.

Boletim do Instituto Brasileiro de Gemas e Metais Preciosos, Núcleo setorial de informação, Ano XIV, n. 48, jul. /set. 2006.

O Setor em grandes números ano 2006. Disponível em: <http://www.ibgm.com.br>. Acesso em: 05 de Fevereiro de 2007.

- Informações Setoriais (Estatísticas - Principais Países Produtores de Ouro em Bruto). Disponível em: <http://www. ibgm.com.br>. Acesso em: 30 de Janeiro de 2007.

KHAN, Z. Cleaner Production: an economical option for ISO certification in developing countries. Journal of Cleaner Production, v. 16, p. 22-27, 2008.

LASTRES, H. M. M. et al. Globalização e inovação localizada. Nota Técnica 01/98. Rio de Janeiro: Instituto de Economia, Universidade Federal do Rio de Janeiro, IE/UFRJ, 1998.

Políticas para promoção de arranjos produtivos e inovativos locais de micro e pequenas empresas: vantagens e restrições do conceito e equívocos usuais, set. 2004. Disponível em: $<$ http//www.redesist.ie.ufrj.br >. Acesso em: Janeiro de 2006.

LEMOS, C. Inovação para arranjos e sistemas produtivos de MPME. In: Proposição de políticas para a promoção de sistemas produtivos locais de micro, pequenas e médias empresas brasileiras. Fase I do projeto, 2001. Disponível em: <http/www. redesist.ie.ufrj.br> . Acesso em: 20 de Junho de 2005.

LUSTOSA, M. C. J.; YOUNG, C. E. Política ambiental. In: KUPFER, D. E.; HASENCLEVER, L. (Orgs.). Economia industrial: fundamentos teóricos e práticas no Brasil. Rio de Janeiro: Elsevier, 2002.

MANUAL DE OSLO/OCDE. Diretrizes para coleta e interpretação de dados sobre inovação. Edição em português. Finep, 2005.

MIGLINO, M. A. P. Inovação: o Local Importa? Um ensaio sobre os nexos entre inovação e espaço segundo autores contemporâneos selecionados. 2003. Dissertação (Mestrado em Política Científica e Tecnológica) - Instituto de Geociência, Universidade Estadual de Campinas.

NORONHA, E. G.; TURCHI, L. Política Industrial e ambiente institucional na análise de arranjos produtivos locais. Brasília, mar. 2005. (Texto para discussão n. 1076.).

OLIVEIRA FILHO, F. A. de. Aplicação do conceito de produção limpa: estudo de uma empresa metalúrgica do setor de transformação do alumínio. Florianópolis, 2001. Dissertação (Mestrado em Engenharia de Produção) - Universidade Federal de Santa Catarina.

SERVIÇO BRASILEIRO DE APOIO ÀS MICRO E PEQUENAS EMPRESAS - SEBRAE. Estudo da Atividade Empresarial Indústrias de Jóias de São José do Rio Preto. Unidade Operacional de Orientação Empresarial - Consultoria de Administração Geral, 2003. (dados não publicados) .

SILVA, G. C. S.; MEDEIROS, D. D. Metodologia de checkland aplicada à implementação da produção mais limpa em serviços. Gestão \& Produção, v. 13, n. 3, p. 411-422, set.-dez. 2006.

SUZIGAN, W. et al. Aglomerações industriais no Estado de São Paulo. Economia Aplicada, v. 5, n. 4, p. 695-717, out-dez. 2001.

. Sistemas locais de produção: mapeamento, tipologia e sugestões de políticas. ANPEN, 2003. Disponível em: <http:// econpapers.repers.org/paper/anpen2003/ e $28 \mathrm{htm}>$. Acesso em: 12 de Dezembro de 2005.

UNITED NATIONS ENVIRONMENT PROGRAMME - UNEP. $\mathbf{P}+\mathbf{L}, 1$ 1989. Disponível em <http:// www.unep.org>. Acesso em: 07 de Maio de 2005.

Cleaner Production Global Status Report. 2002. Disponível em <http:// www.unep.org>. Acesso em: 07 de Maio de 2005.

UNIDO/UNEP. Manual de avaliação de $\mathbf{P}+\mathbf{L}$. Traduzido por CNTL/SENAI. Porto Alegre, 1995.

UNITED NATIONS INDUSTRIAL DEVELOPMENT ORGANIZATION - UNIDO. Produção mais Limpa. Disponível em < http://www.unido.org/doc/4460 >. Acesso em: 09 de Setembro de 2006.

\section{Sobre os autores}

\section{Rosely Mana Domingues}

Centro Universitário de Rio Preto - UNIRP

Av. Jornalista Roberto Marinho, Km 183, CEP 15061-500, Jardim Primavera - São José do Rio Preto - SP, Brasil e-mail: roselyrp@redecidade.com

\section{Sônia Regina Paulino}

Programa de Pós-Graduação em Desenvolvimento Regional e Meio Ambiente, Universidade de Araraquara - UNIARA Curso de Gestão Ambiental, Escola de Artes, Ciências e Humanidades - EACH, Universidade de São Paulo - USP Av. Arlindo Bettio, 1000, CEP 03828 000, São Paulo - SP, Brasil e-mail: sonia.paulino@usp.br 